\title{
EXTRAÇÃo SELETIVA DE CO2 2 PARA ANÁLISE dOS ISÓTOPOS DE CARBONO E OXIGÊNIO EM AMOSTRAS DE MULTICARBONATOS: MAGNESITA-DOLOMITA
}

M.Z.Moreira ${ }^{1}$

T.I.R.Almeida ${ }^{2}$

A obtenção de medidas precisas da composição isotópica de $\mathrm{C}$ e $\mathrm{O}$ em diferentes carbonatos coexistentes é essencial para a interpretação dos dados. A separação física é difícil, justificando a tendência na utilização de métodos químicos, através de ataque por $\mathrm{H}_{3} \mathrm{PO}_{4}$ a $100 \%$ em diferentes temperaturas e tempos de reação.

Os procedimentos para o ataque ácido de carbonatos especfficos estão bem descritos na literatura, particularmente para calcita e dolomita, não ocorrendo o mesmo para composições mistas. AL-AASM et al. (1990; Chemical Geology, 80:119-125) propõem metodologia para estudos de calcita-dolomita-magnesita-siderita, a partir de carbonatos puros, precipitados em laboratório fase a fase e posteriormente misturados. Aqueles autores indicam a necessidade de ataques ácidos mais longos e a temperaturas mais elevadas que as indicadas na literatura, salientando o perigo de contaminação entre fases carbonáticas.

O objetivo da pesquisa ora apresentada foi verificar a replicação dos dados de ALAASM et al. (op.cit.) em uma amostra natural (magnesitito do tipo Veitsch de idade proterozóica, coletada na Mina de Campo de Dentro, Brumado, Bahia), composta quase que exclusivamente por magnesita, como verificado quimicamente e por difratometria de raio $\mathrm{X}$.

Inicialmente fez-se a extração de $\mathrm{CO}_{2}$ relativo a dolomita $\left(\mathrm{H}_{3} \mathrm{PO}_{4}, 72\right.$ horas a $\left.25^{\circ}\right)$, em duas aliquotas de amostra. A seguir ambas foram atacadas por $\mathrm{H}_{3} \mathrm{PO}_{4}$ a $100 \%$, a 50 e a $25^{\circ} \mathrm{C}$. $\mathrm{Na}$ primeira aliquota verificou-se a produção de $60 \mathrm{mmHg}$ de pressão relativa após 72 horas, com abertura

\footnotetext{
${ }^{1}$ Seção de Hidrologia e lsótopos Estáveis, CENA, USP.

${ }^{2}$ Departamento de Geologia Econômica e Geologia Aplicada, Instituto de Geociências, USP.
} 
de $26 \%$ da amostra (contra cerca de $5 \%$ em Al-Aasm). Após 169 horas de reação, houve abertura de $42 \%$ do carbonato (contra cerca de $10 \%$ de Al-Aasm), mantendo relativa estabilidade isotópica - menor que o êrro analftico de $\pm 0,3 \%$ - nas extrações feitas a 72, 96 e 169 horas, implicando em um ataque de no mínimo 72 horas (contra 240 de Al-Aasm). Comprovou-se assim que os parâmetros de PERRY \& TAN (1972; Geol.Soc.Am.Bull., 83:647-664) - $50^{\circ} \mathrm{C}$ e 72 horas - são adequados para o estudo de magnesita natural e em condições mais compativeis à rotina laboratorial que as propostas por ALAASM et al. (op.cit.). A segunda alíquota foi atacada a $25^{\circ} \mathrm{C}$, verificando-se haver reação, ainda que extremamente lenta, com abertura de $15 \%$ da amostra após 1.144 horas e relativa estabilização do conteúdo isotópico a partir de 144 horas.

Pode-se explicar a não replicação dos dados obtidos em amostra de rocha com carbonatos puros, precipitados em laboratório, devido à mais perfeita simetria das celas unitárias que ocorre em um composto puro. Uma amostra natural de magnesita do tipo Veitsch, por conter diversos microcomponentes em sua estrutura cristalina, será mais susceptível ao ataque ácido.

Já a abertura parcial da magnesita após 169 horas de reação a $50^{\circ} \mathrm{C}$ corrobora as observações de AL-AASM et al. (op. cit.) no que se refere à possibilidade de contaminação entre fases carbonáticas. Este problema será desprezível em amostras onde o carbonato menos reativo predominar sobre o mais reativo. Em situações em que o inverso ocorrer, recomenda-se um ataque ácido mais enérgico ou prolongado, como propõem AL-AASM et al. (op. cit). 